\title{
CORRESPONDENCE
}

\section{Lower Limb Amputation in Germany}

An Analysis of Data From the German Federal Statistical Office Between 2005 and 2014

by Prof. Dr. med. Knut Kröger, Dr. med. Christian Berg, Dr. med. Frans Santosa, Dr. med. Nasser Malyar, and Prof. Dr. med. Holger Reinecke in issue 8/2017

\section{Treat Foot Ulcers Conservatively}

When discussing the possible causes for the decrease in the rate of major amputations, Kröger et al. (1) pointed out the protective effect of podological treatment. And quite rightly so, as a recent study from the US confirms (2).

Regarding minor amputations, it needs to be mentioned that many such amputations are undertaken only because osteomyelitis has been detected, although amputation would not have been necessary. In my experience, many foot ulcers with osteomyelitis can successfully be treated conservatively and made to heal by using appropriate therapies (pressure relief and, if needed, antibiotic therapy and revascularization).

DOl: 10.3238/arztebl.2017.0399a

\section{REFERENCES}

1. Kröger K, Berg C, Santosa F, Malyar N, Reinecke H: Lower limb amputation in Germany —an analysis of data from the German Federa Statistical Office between 2005 and 2014. Dtsch Arztebl Int 2017; 114: 130-6.

2. Schmidt BM, Wrobel JS, Munson M, Rothenberg G, Holmes CM: Podiatry impact on high-low amputation ratio characteristics: a 16-year retrospective study. Diabetes Res Clin Pract 2017; 126: 272-7.

Dr. med. Dipl. oec. troph. Tony Tanudjaja

Diabetologische Schwerpunktpraxis,

Fußambulanz, Hausärztliche Versorgung, Düsseldorf ttanudjaja@gmx.de

\section{Conflict of interest statement}

The author declares that no conflict of interest exists.

\section{Podological Treatment Has a Protective Effect}

The results (1) are consistent with earlier reports of amputations in diabetes mellitus. In 2016 May et al. reported a decrease in rates of amputations of the foot in patients insured with a German statutory sickness fund since 2007, and Hagen et al. reported a drop in the incidence of amputations in participants in the disease management program (DMP) for type 2 diabetes since $2003(2,3)$. In diabetes patients, the decrease in the rate of amputations occurred in tandem with the increase in podological treatment services, according to sickness funds' reports on medical prescriptions. If podological treatment is prescribed on a regular basis, fewer amputations take place, as Kröger et al. showed in their recent data analysis - a welcome finding (4).

\section{REFERENCES}

1. Kröger K, Berg C, Santosa F, Malyar N, Reinecke H: Lower limb amputation in Germany - an analysis of data from the German Federa Statistical Office between 2005 and 2014. Dtsch Arztebl Int 2017; 114: $130-6$

2. May M, Hahn S, Tonn C, Engels G, Hochlenert D: Decrease in (major) amputations in diabetics: a secondary data analysis by AOK Rheinland/Hamburg. J Diabetes Res 2016, Article ID 6247045

3. Hagen B, Groos S, Kretschmann J, Weber A, Altenhofen L: Rückgang der Inzidenz von Amputationen, der Dialysepflicht und von Erblindungen in den Patientenkohorten 2003-2010. Befunde aus dem Disease Management Programm (DMP) Diabetes mellitus Typ 2 in Nordrhein. Abstrakt P95. Diabetologie \& Stoffwechsel 2015; 10: 28

4. Kröger K, Moysidis T, Feghaly M, Schäfer E, Bufe A, on behalf of the Initiative Chronische Wunden e. V., Germany: Association of diabetic foot care and amputation rates in Germany. Int Wound J 2016; 13 : $686-91$.

Prof. (i.R.) Dr. med. Ernst-Adolf Chantelau

Bremen

chantelau@gmx.de

Conflict of interest statement

The author declares that no conflict of interest exists.

\section{Interdisciplinary collaboration is important in peripheral arterial disease}

Kröger et al. described a welcome fall in the rate of major amputations in patients with peripheral arterial disease (PAD) and diabetes mellitus. Simultaneously they found that the rate of minor amputations has risen. The article is very detailed and carefully researched and includes the evaluation of data from 2005-2014.

In the article's discussion section, the authors point out that PAD of the limbs can be treated very effectively by using interventional vascular surgery (1). Emphasis is put on the interdisciplinary approach in this setting. We welcome and appreciate this approach very much indeed. However, as plastic and esthetic surgeons we miss the mention of microsurgical reconstruction using flaps to cover large defects on the lower limb in patients with diabetes and PAD (2). In our view, these constitute effective and safe options for treating defects with exposed functional structures to a sufficient and sustained extent. The interdisciplinary setting in particular makes it possible to form an anastomosis of free flaps to autologous venous bypass grafts, which at the same time improves perfusion $(2,3)$.

By routinely involving plastic surgeons, the options improve for covering defects on the lower extremity in a timely manner, which in turns leads to a fall in minor and major amputation rates and improves affected patients' quality of life. D0l: 10.3238/arztebl.2017.0399c

\section{REFERENCES}

1. Kröger K, Berg C, Santosa F, Malyar N, Reinecke H: Lower limb amputation in Germany - an analysis of data from the German Federa Statistical Office between 2005 and 2014. Dtsch Arztebl Int 2017; 114: 130-6. 
2. Schirmer S, Ritter RG, Fansa H: Vascular surgery, microsurgery and supramicrosurgery for treatment of chroinic diabetic foot ulcers to prevent amputations. PloS One 2013; 8.

3. Daigeler A, Kneser U, Fansa H, Riester T, Uder M, Horch RE: Reconstruction of the vascular compromised lower extremity —report of the consensus workshop of the 35. meeting of the DAM (Deutschsprachige Gemeinschaft für Mikrochirurgie der peripheren Nerven und Gefäße) 2013 in Deidesheim. Handchir Mikrochir Plast Chir 2014; 46: 248-55.

Dr. med. Steffen Schirmer

Department für Plastische und Ästhetische Chirurgie

Helios Klinikum Berlin Buch

Steffen.Schirmer@helios-kliniken.de

Prof. Dr. med. Hisham Fansa, MBA

Gemeinschaftspraxis Prof. Heitmann \& Prof. Fansa, München

Conflict of interest statement

The authors declare that no conflict of interest exists.

\section{In Reply:}

Tanudjaja mentions a US publication that describes the importance of podiatry for amputation rates (1). Even though the study's subject matter fits well with our results (2), the term podology as foot care administered by medical professionals needs to be carefully distinguished from podiatry, a science that focuses in the study of the foot, its anatomy, physiology and pathophysiology, and the correct treatment. Podologists are not allowed to make incisions and are not allowed to treat wounds, whereas podiatrists, as physicians, are obviously allowed to do so. Podiatry is a medical subdiscipline especially in the Anglo-American area, which has not become established in Germany so far. The option to prescribe podological treatment to patients with diabetic foot syndrome, with the expense covered by the health insurers, is a particularity of the German healthcare system that hardly exists anywhere else in the world.

The problem of all comparison studies on the subject of amputation is the fact that the decision to amputate and its timing are often made on a highly individual basis, and that hardly any generally applicable criteria exist that would make the indication for amputation objectively verifiable. The statement is therefore entirely correct, that many minor amputations have been undertaken only on the basis of detected osteomyelitis, although no pressing need existed to do so.

We thank Chantelau for the additional literature citations. Especially the publication by May et al. on data of patients in the German statutory sickness fund scheme (3) deserves highlighting, as it is based on individualized patients and their progress - unlike our own publication. The study by May et al. focuses on the prevention of amputations by means of interdisciplinary collaborations. It is nigh-on impossible to put in numbers the effect of networks and their added value for the diabetic foot syndrome, as networks are based on the will to collaborate and the ability to communicate with one another. Neither of these factors is reflected in the system of diagnosis-related groups and in outpatient billing systems, but they are crucial for the success of a network.

Schirmer and Fansa are, of course, right to point out the option of microsurgical flap reconstruction to cover large defects in the lower limb in patients with diabetes and peripheral arterial occlusive disease. Interdisciplinary collaboration in particular makes it possible to form an anastomosis between free flaps and autologous venous bypass grafts, which simultaneously improve perfusion. In our experience, however, a minority of plastic surgeons is enthused by working on the diabetic foot syndrome, and the result of their work also depends on whether the patient from the network is presented at the right time and, having had microsurgery, s/he receives an adequate long-term follow-up. DOI: 10.3238/arztebl.2017.0400

\section{REFERENCES}

1. Schmidt BM, Wrobel JS, Munson M, Rothenberg G, Holmes CM: Podiatry impact on high-low amputation ratio characteristics: a 16-year retrospective study. Diabetes Res Clin Pract 2017; 126: 272-7.

2. Kröger K, Berg C, Santosa F, Malyar N, Reinecke H: Lower limb amputation in Germany - an analysis of data from the German Federal Statistical Office between 2005 and 2014. Dtsch Arztebl Int 2017; 114: 130-6.

3. May M, Hahn S, Tonn C, Engels G, Hochlenert D: Decrease in (major) amputations in diabetics: a secondary data analysis by AOK Rheinland/Hamburg. J Diabetes Res 2016, Article ID 6247045.

Prof. Dr. med. Knut Kröger

Klinik für Gefäßmedizin

HELIOS Klinikum Krefeld GmbH, Krefeld

knut.kroeger@helios-kliniken.de

Dr. med. Christian Berg, Dr. med. Frans Santosa

Dr. med. Nasser Malyar, Prof. Dr. Holger Reinecke

\section{Conflict of interest statement}

Prof. Kröger has received reimbursement of conference attendance fees and trave costs as well as payments for lectures from UCB Pharma, Sanofi, and Bayer.

Prof. Reinecke has received payments for consultancy from Bristol-Myers, Pfizer, and Pluristem. Study support (third-party funding) was provided to him by Pluristem, Bard, Bayer, and Biotronik.

The remaining authors declare that no conflict of interest exists. 